\title{
Demand for surgical sterilization among patients in a district maternity hospital
}

\author{
L. J. OPIT AND MARY E. BRENNAN \\ Health Services Research Centre, Medical School, University of Birmingham, B15 2TJ
}

\begin{abstract}
SumMary
In a large district maternity hospital 1,079 women patients were interviewed about the perceived need for surgical sterilization. Of the patients interviewed $3.7 \%$ had been booked for this procedure and a further $8.7 \%$ expressed a desire to undergo sterilization at the time of interview. This wish was not limited to European women but was frequently expressed among the immigrant groups.

A sample of patients' husbands, contacted by means of a questionnaire about vasectomy, revealed that $10.7 \%$ of the sample of 262 replying would request immediate vasectomy if this were available. Some implications for planning any extension of these services are discussed.
\end{abstract}

\section{INTRODUCTION}

During the last six years there has been a considerable growth of the use of surgical sterilization as a part of the procedure of contraception (Buckle and Loung, 1971). The growth stems from several causes but in the last instance has depended on an increased willingness of consultant obstetricians to offer this option to their patients.

This paper presents part of an enquiry into the needs for family planning services by the patients who attended a large district maternity hospital for confinement during the last quarter of 1972. The enquiry included an assessment of the availability of sterilization procedures for these patients and their husbands, as this service is properly part of the therapeutic armamentarium of an effective family planning service.

The paper reports the demand for surgical sterilization as it is perceived by this group of patients and their husbands.

\section{METHOD}

All patients living within the Coventry Local Authority area and admitted to the Walsgrave Hospital for confinement were selected for interview during a three-month period in 1972. This hospital provides all the inpatient maternity beds for the city, and during the period of the survey $88 \cdot 3 \%$ of all births in Coventry occurred in the hospital (Coventry M.O.H., 1973). Every woman was offered the opportunity to refuse interview after a preliminary assessment of fitness by the clinical staff of the hospital. The interview was structured and carried out by married women with considerable nursing or health visitor experience. One interviewer spoke the languages of the major immigrant population groups (Punjabi and Hindi). The details of the interview were recorded on an appropriate questionnaire and subsequently transferred to IBM cards on which analysis was conducted using an IBM counter sorter.

To obtain data on male sterilization a sample of patients' husbands was contacted by leaving appropriate forms with the patient for the husband or partner to complete during or after visiting times. These forms were collected on discharge of the patient from hospital. This procedure was used for every patient during the last five weeks of the study period.

\section{RESULTS}

During the three months of the survey 1,129 women were approached for interview and this represents $91 \%$ of all confinements occurring in the hospital during this period. Of $1,129,30$ were assessed by the clinical staff as unfit for interview on medical or psychological grounds and 20 women refused to be interviewed. A demographic analysis of the patients has been published separately as well as details relating to the need for contraceptive advice (Brennan and Opit, 1973).

During the interview patients were asked whether they would like to be sterilized within a few weeks of their present confinement, if this could be arranged. The response to this enquiry is shown in Table I. As the table indicates, sterilization had already been arranged for about $3 \cdot 7 \%$ of the sample of women who were interviewed. Our enquiry 
TABLE I

DISTRIBUTION OF PATIENTS ACCORDING TO DESIRE FOR IMMEDIATE STERILIZATION

\begin{tabular}{|c|c|c|c|c|c|c|c|c|}
\hline & $\begin{array}{l}\text { European } \\
\text { Protestant }\end{array}$ & $\begin{array}{l}\text { European } \\
\text { Catholic }\end{array}$ & $\begin{array}{c}\text { European } \\
\text { Other }\end{array}$ & $\begin{array}{c}\text { West } \\
\text { Indian }\end{array}$ & Sikh & Hindu & Moslem & Total \\
\hline No. of patients replying & 644 & 224 & 30 & 6 & 71 & 31 & 29 & 1.035 \\
\hline Sterilization arranged $\quad \ldots$ & $\begin{array}{l}3.9 \% \\
(25)\end{array}$ & $5 \cdot 4 \%$ & - & - & $1.4 \%$ & - & - & $3 \cdot 7 \%$ \\
\hline Sterilization desired now $\ldots$ & $8 \cdot 7 \%$ & $10 \cdot 3 \%$ & 一 & 一 & $9.9 \%$ & $6.4 \%$ & $3.6 \%$ & $8 \cdot 6 \%$ \\
\hline Sterilization not desired now & $81 \cdot 8 \%$ & $81 \cdot 2 \%$ & $96 \cdot 7 \%$ & $100 \%$ & $83 \cdot 1 \%$ & $80 \cdot 6 \%$ & $96.4 \%$ & $82 \cdot 7 \%$ \\
\hline Undecided $\quad \ldots \quad \ldots$ & $5 \cdot 6 \%$ & $3 \cdot 1 \%$ & $3 \cdot 3 \%$ & - & $5 \cdot 6 \%$ & $13 \%$ & - & $5 \cdot 0 \%$ \\
\hline
\end{tabular}

Numbers of patients are shown in parentheses

In 44 patients the recorded data were incomplete

suggested, however, that there were still more women who desired sterilization, amounting, in fact, to a further $8.6 \%$ of all patients interviewed. Quite clearly this estimate of $8.6 \%$ may well be reduced when further discussion about the procedure has taken place, but it seems likely that there is a considerable unmet need. This interest in surgical sterilization was not restricted to Europeans for both Sikh and Hindu women also seemed anxious to have this facility available. The West Indian group was very small and unusual, inasmuch as half the women were unmarried, and this may well account for the results in this group.

Examination of the hospital's records showed that during a six-month interval, including this survey period, 90 postpartum sterilizations were carried out, and this corresponds to approximately $3.8 \%$ of all deliveries in the hospital. This supports the belief that our interviewed sample was representative of the admissions during the longer intelval.

\section{Characteristics of Group desiring Sterillzation}

It is of importance to compare the group desiring sterilization with those for whom it had already been arranged as this indicates, partially, the criteria being adopted in selecting women for this procedure. The patients' ages and gravidity in these two groups are shown in Tables II and III. The patients already selected for sterilization were in the main over 25 years of age and had had three or more completed pregnancies, while an examination of the age and parity characteristics of patients desiring sterilization in Table III suggests that there are an additional 46 women in this category who had not been offered this procedure. Thus we may compute the potential demand for postpartum sterilization as the total number of patients booked plus all patients aged 26 years and over with three or more children who desired sterilization. This gives a rate of 81 per 1,000 confinements. Even if, after further
TABLE II AGE AND PARITY CHARACTERISTICS OF PATIENTS
BOOKED FOR STERILIZATION

\begin{tabular}{|c|c|c|c|c|c|c|}
\hline \multirow{2}{*}{$\begin{array}{c}\text { Age at } \\
\text { Confine- } \\
\text { ment } \\
\text { (years) }\end{array}$} & \multicolumn{5}{|c|}{ No. of Pregnancies (including present one) } & \multirow[b]{2}{*}{ Total } \\
\hline & 1 & 2 & 3 & 4 & $\begin{array}{c}5 \text { or } \\
\text { more }\end{array}$ & \\
\hline \multirow{2}{*}{$\begin{array}{l}20 \text { or less } \\
21-25 \quad \ldots \\
26-30 \quad \ldots \\
31-35 \quad \ldots \\
\text { More } \\
\text { than } 35 \quad \ldots\end{array}$} & $\begin{array}{l}0 \\
0 \\
0 \\
0\end{array}$ & $\begin{array}{l}0 \\
0 \\
1 \\
0\end{array}$ & $\begin{array}{l}0 \\
2 \\
2 \\
2\end{array}$ & $\begin{array}{l}0 \\
1 \\
2 \\
1\end{array}$ & $\begin{array}{l}0 \\
0 \\
6 \\
9\end{array}$ & $\begin{array}{r}0 \\
3 \\
11 \\
12\end{array}$ \\
\hline & 1 & $\mathbf{0}$ & 0 & 1 & 10 & 12 \\
\hline Total & 1 & 1 & 6 & 5 & 25 & 38 \\
\hline
\end{tabular}

TABLE III

AGE AND PARITY CHARACTERISTICS OF PATIENTS DESIRING STERILIZATION

\begin{tabular}{|c|c|c|c|c|c|c|}
\hline \multirow{2}{*}{$\begin{array}{c}\text { Age at } \\
\text { Confine- } \\
\text { ment } \\
\text { (years) }\end{array}$} & \multicolumn{5}{|c|}{ No. of Pregnancies (including present one) } & \multirow[b]{2}{*}{ Tota } \\
\hline & 1 & 2 & 3 & 4 & $\begin{array}{l}5 \text { or } \\
\text { more }\end{array}$ & \\
\hline \multirow{2}{*}{$\begin{array}{l}20 \text { or less } \\
21-25 \quad \ldots \\
26-30 \quad \ldots \\
31-35 \quad \ldots \\
\text { More } \\
\text { than } 35 \ldots\end{array}$} & $\begin{array}{l}1 \\
1 \\
1 \\
0\end{array}$ & $\begin{array}{r}2 \\
10 \\
5 \\
1\end{array}$ & $\begin{array}{r}0 \\
15 \\
17 \\
6\end{array}$ & $\begin{array}{l}1 \\
2 \\
5 \\
2\end{array}$ & $\begin{array}{l}\mathbf{0} \\
\mathbf{3} \\
\mathbf{4} \\
\mathbf{7}\end{array}$ & $\begin{array}{l}4 \\
31 \\
32 \\
16\end{array}$ \\
\hline & 0 & 0 & 2 & 1 & 2 & 5 \\
\hline Total & 3 & 18 & 40 & 11 & 16 & 88 \\
\hline
\end{tabular}

(One patient desiring sterilization is not shown as the details of age were incomplete).

discussion and thought, only $50 \%$ of the second group still wished for sterilization, this would give a rate of 60 sterilizations per 1,000 confinements as the potential need for this service. It is interesting to note that this rate is identical with that found in those departments of obstetrics reporting a liberal policy in this regard (Buckle and Loung, 1971).

As many of the women were young and obviously had not completed their families, enquiry was made as to whether these patients believed that they might eventually desire sterilization as a method of contraception. The answers to this question are set 
TABLE IV

DISTRIBUTION OF PATIENTS ACCORDING TO DESIRE FOR EVENTUAL STERILIZATION

\begin{tabular}{|c|c|c|c|c|c|c|c|c|c|}
\hline & & $\begin{array}{l}\text { European } \\
\text { Protestant }\end{array}$ & $\begin{array}{l}\text { European } \\
\text { Catholic }\end{array}$ & $\begin{array}{l}\text { European } \\
\text { Other }\end{array}$ & $\begin{array}{c}\text { West } \\
\text { Indian }\end{array}$ & Sikh & Hindu & Moslem & Total \\
\hline No. of patients replying & .. & 563 & 189 & 30 & 6 & 63 & 29 & 28 & 908 \\
\hline 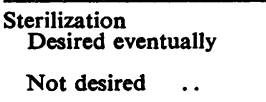 & $\cdots$ & $\begin{array}{l}19.9 \% \\
(112) \\
67.4 \%\end{array}$ & $\begin{array}{c}14 \cdot 3 \% \\
(27) \\
72 \cdot 5 \%\end{array}$ & $\begin{array}{l}20 \% \\
(6) \\
70 \%\end{array}$ & $\begin{array}{c}66 \cdot 7 \% \\
(4) \% \\
16 \cdot 7 \%\end{array}$ & $\begin{array}{l}19 \cdot 1 \% \\
(12) \\
42 \cdot 9 \%\end{array}$ & $\begin{array}{l}27 \cdot 6 \% \\
37(8) \% \\
37 \cdot 9 \%\end{array}$ & $\begin{array}{c}0 \% \\
(0) \\
85 \cdot 7 \%\end{array}$ & $\begin{array}{l}18 \cdot 6 \% \\
81.4 \%\end{array}$ \\
\hline Undecided & .. & $12.6 \%$ & $13 \cdot 2 \%$ & $10 \%$ & $16 \cdot 7 \%$ & $38 \cdot 0 \%$ & $34 \cdot 5 \%$ & $14 \cdot 3 \%\}$ & \\
\hline
\end{tabular}

This table includes only answers from patients for whom early sterilization was not desired or arranged Numbers of positive replies are shown in parentheses

out in Table IV. The table shows answers only from patients who did not want immediate surgical sterilization or who were undecided about this.

Once again these answers demonstrate that there is a large potential demand for sterilization. This demand is present not only in the local population but also in the immigrant groups, only the Moslem women rejecting surgical sterilization as a contraceptive procedure.

Throughout the Birmingham region postpartum sterilization has been developing as a standard contraceptive technique, although there is considerable variation in the number performed from group to group, which probably reflects the differing views and ethical beliefs of the consultant obstetricians more than differences in the demand for sterilization by the patients themselves. The average regional rate for postpartum sterilization during the survey period was 26 per 1,000 confinements with variation in individual groups from a maximum of 64 to a minimum of 0 . The average rate in this region is very close to that reported by Blacker and Peel for a national survey (Blacker and Peel, 1969).

Our results suggest that the need for this service as expressed by the patient's wishes probably lies between 60 and 80 per 1,000 confinements.

\section{IMPLICATIONS}

It is possible to forecast, approximately at least, some effects of increasing the number of women offered sterilization. In a previous paper we reported the number of births declared by patients as unwanted (Brennan and Opit, 1973). Further analysis of these data shows that the patients expressing a wish for sterilization contain $18 \%$ of these unwanted pregnancies, and if the group of patients for whom sterilization had been performed or arranged is included, these two groups above contain the $27 \%$ of all declared unwanted pregnancies.
It is difficult to calculate the effect of surgical sterilization on the expected number of births but an approximate estimate for Coventry can be obtained from our study by using data related to age or parity. This requires an assumption that age patterns of fertility and conception will not change greatly over the next five years. Our results showed that $15.5 \%$ of women with three children and $31.1 \%$ of women with four or more children wished to be sterilized or had had sterilization arranged. These figures exclude any women less than 26 years of age since few would have been accepted for the procedure. The ratios of births of order $n+1$ to those of order $n$ gives an approximate measure of the likelihood of one further childbirth after the $n$th child. These results enable an estimate of births saved to be made. Application then of the liberal policy of allowing all women over 25 years with three or more children to be sterilized if they desire it would prevent 59 births per 100 sterilizations spread over 10 to 15 years with most prevented births in the first five years.

Although the justification for offering surgical sterilization to women must depend entirely on the balance of likely benefit to the individual who undergoes the procedure, the use of sterilization itself generates implications for the hospital services and the community as a whole. The cost of this action can be calculated approximately by noting that in 1972 an analysis of 1,489 cases of postpartum sterilization showed that these patients required an average of $4 \cdot 8$ additional days in hospital compared with other maternity cases in the Birmingham region (Wall, 1973). Laing (1972) has shown that considerable financial benefits can accrue from savings in the social services when unwanted pregnancies are prevented, while the implications to the health services are more complex, reducing obstetric and paediatric case load directly and influencing gynaecological work load indirectly (Muldoon, 1972). 
TABLE V

DEMAND FOR VASEcTOMY

\begin{tabular}{|c|c|c|c|}
\hline & & No. & $\%$ \\
\hline $\begin{array}{l}\text { Procedure unnecessary as wife ha } \\
\text { sterilized } \\
\text { Vasectomy already arranged } \\
\text { Would like vasectomy now } \\
\text { Would like vasectomy eventually } \\
\text { Would not like vasectomy ... } \\
\text { Don't know or undecided } . . \\
\text { Refused to answer }\end{array}$ & $\begin{array}{ll}\text { agreed to be } \\
\ldots & \cdots \\
\ldots & \cdots \\
\ldots & \cdots \\
\ldots & \cdots \\
\ldots & \cdots \\
\ldots & \cdots\end{array}$ & $\begin{array}{r}3 \\
3 \\
28 \\
38 \\
92 \\
92 \\
6\end{array}$ & $\begin{array}{r}0 \cdot 7 \\
0 \cdot 7 \\
6 \cdot 1 \\
8 \cdot 3 \\
20 \cdot 0 \\
20 \cdot 0 \\
1 \cdot 3\end{array}$ \\
\hline \multicolumn{2}{|l|}{ Total No. of questionnaires returned } & 262 & $57 \cdot 1$ \\
\hline
\end{tabular}

Percentages shown are based on the total number of questionnaires circulated (459).

\section{VASECTOMY}

As vasectomy has become an important and acceptable solution to the control of fertility an attempt was made to ascertain the potential need for this procedure among the husbands of the interviewed women. During the study 459 questionnaire forms were circulated to patients' husbands and 262 forms were returned and analysed. The results of this enquiry are set out in Table V. As a large number of forms were not returned it is difficult to assess the numerical significance of these rates of demand and we have assumed that all missing forms would score as undecided in arriving at the rates in Table V. Surprisingly, $6.1 \%$ of the sample indicated willingness to undergo the procedure of vasectomy, and of these 28 men, the majority (17) had partners who did not wish to be sterilized. Thus, in this sample at least, vasectomy appears to be complementary to the surgical sterilization of women. About $20 \%$ of the men indicated unambiguously that they did not approve of vi rectomy for themselves but even $80 \%$ of this group on men thought that the procedure should be available for those who required it.

If the proportion of men requiring vasectomy in our survey is representative of the population attending this hospital, then there could be a need for an additional 250 to 500 vasectomies annually in a population of 400,000 . This would certainly have the effect of reducing the number of female sterilizations and might well represent a considerable saving in hospital resources, as well as a probable gain in safety.

\section{Discussion}

The decision to perform surgical sterilization cannot be made lightly and it is not the purpose of this paper to suggest otherwise; nor are we concerned with discussing the timing or technique even though these are important related issues.
Our first interest was to explore the patients' need for sterilization as they perceived it themselves as a contraceptive procedure. Our study suggests that there are a considerable number of patients who desire sterilization after childbirth and who, superficially, fulfill the criteria of those patients who have already been offered this procedure.

As Davidson and Donald (1972) have argued, younger marriage and a longer period of fertility are creating a need for 20 to 30 years of contraceptive cover in many women, and this produces some anxiety about the side effects of a number of the current contraceptive methods. At the same time the reduction of infant and childhood mortality has increased the chance of determining the desired family size securely, within 10 years of marriage. In addition, multiple pregnancies can induce a chain of events leading to many of the gynaecological illnesses. With these arguments as the background to the use of surgical sterilization for contraception, it is necessary to consider the problems created by this procedure. A study by Thompson and Baird (1968) of women some years after sterilization has revealed that $90 \%$ of the women studied were completely satisfied with the decision to be sterilized. However, considerable difficulty can arise in patients who subsequently wish to bear children, and the irreversible nature of the sterility induced by most techniques creates the need for care in selecting women for the procedure.

One other important issue relates to the safety of surgical sterilization. It is difficult, from published data, to obtain a clear idea of morbidity and mortality from the various techniques as they are practised in the United Kingdom. Davidson and Donald (1972) reported the results of 810 procedures, mostly laparoscopic tubal coagulation, and this series contained no deaths, although a small number of patients required subsequent laparotomy. No deaths were noted in 1,489 cases recorded in the Birmingham region during 1972, and while Buckle and Loung (1971) recorded two deaths in 1,289 cases and Murdoch (1969) estimated the mortality as 2 per 1,000 from a survey of 25,000 cases. this must be compared with 0.58 deaths per 1,000 confinements for women aged over 35 years (Buckle and Loung, 1971).

One major advantage of vasectomy over surgical sterilization of women lies in its safety and freedom from serious morbidity when competently performed (Simon Population Trust, 1969). The particular problem of vasectomy as a means of fertility control is that of acceptability, especially to men of 
social classes IV and V, but it seems likely that this procedure will become more popular, leading to an increased demand.

It is quite clear that more information is needed about the selection, timing, and safety of various techniques of surgical sterilization, but we believe that this survey has shown a considerable unmet need and should encourage a more complete appraisal of the technical, logistic, and financial issues involved.

The authors wish to acknowlege the help of the Birmingham Regional Hospital Board for financing this enquiry, and the staff, both consultants and general practitioners, of the Walsgrave Maternity Hospital for allowing us access to their patients.

\section{REFERENCES}

Blacker, C. P. and Peel, J. H. (1969). Sterilization of women. Brit. med. J., 1, 566.
Brennan, Mary E. and Opit, L. J. (1973). Demand for family planning advice amongst patients in a district maternity hospital. Brit. med. J., 3, suppl., p. 19.

Buckle, A. E. R. and Loung, K. C. (1971). Sterilization of the female: a positive approach to family limitation. J. biosoc. Sci., 3, 289.

Davidson, A. C. and Donald, I. (1972). Female sterilization. Scot. med. J., 17, 210.

LAING, W. A. (1972). The Costs and Benefits of Family Planning. PEP Broadsheet 534. London.

Muldoon, M. J. (1972). Gynaecological illness after sterilization. Brit. med. J., 1, 84.

MURDOCH, R. (1969). Complications of sterilization: Report of scientific meeting at Royal College of Obstetricians and Gynaecologists. J. Obstet. Gynaec. Brit. Cwlth, 76, 1043.

Simon PopUlation Trust (1969). Vasectomy: Followup of a Thousand Cases. Cambridge.

THOMPSON, B. and BAIRD, D. (1968). Follow-up of 186 sterilised women. Lancet, 1, 1023.

WaLl, MARY (1973). Personal communication. 